\title{
'Augmented Reality' Technology and the Dissemination of Historical Graffiti in the Temple of Debod
}

\author{
Miguel Ángel Molinero Polo, ${ }^{1}$ Alfonso Martín Flores, ${ }^{2}$ \\ Jorge Martín Gutiérrez, ${ }^{1}$ Cristóbal Ruiz Medina, ${ }^{1}$ Lucía Díaz-Iglesias Llanos, ${ }^{3}$ \\ Fernando Guerra-Librero Fernández, ${ }^{4}$ Daniel Miguel Méndez Rodríguez, ${ }^{1}$ \\ Luis Navarrete Ruiz, ${ }^{5}$ Manuel Rivas Fernández, ${ }^{1}$ Ovidia Soto Martín ${ }^{1}$
}

\author{
${ }^{1}$ Universidad de La Laguna, Tenerife, Canary Islands; ${ }^{2}$ Museo de San Isidro, Madrid; \\ ${ }^{3}$ Consejo Superior de Investigaciones Científicas, Madrid; ${ }^{4}$ Ártyco. Arte Consery $\equiv$ y Restauración, Madrid; \\ ${ }^{5}$ Baluarte. Gestión de Patrimonio y nuevas tecnología,
}

\begin{abstract}
This contribution presents a digital tool, created with the intention of disseminating a part of the results generated by the Tahut Project: the historical graffiti carved on the walls of the temple of Debod. It also deals with the practical problems encountered during the development of the tool. This is an application made available for the visitors of the monument, providing them with information in an appealing manner, through 'Augmented Reality': complementary images and explanations are received in the visitors' smart-phones or tablets as they read across the walls. In its first version, a printed document is necessary as medium to activate the application. The user can choose between Spanish or English to listen to brief notices about the most significant types of graffiti. The results of this experience are under evaluation in order to apply its lessons to future methods of disseminating the rest of the project's materials: reliefs, inscriptions, history, and development of the temple.
\end{abstract}

Keywords

Temple of Debod; 'Augmented Reality'; graffiti; dissemination methods; museums

The Tahut Project focuses on the study of the reliefs, inscriptions, and graffiti of the Temple of Debod and, by extension, on the entire historical documentation concerning the sanctuary. ${ }^{1}$ In this article a didactic digital tool is presented, developed to make available the results of a specific part of the research to the general public: the historical graffiti. ${ }^{2}$ This contribution also deals with the problems arising when developing this tool and how they have been solved so far. It is based on a new tec $\pi$ gy, scarcely known because of its recent appearance ugmented Reality'. Despite its novelty, there is already evidence of its use as a media for dissemination in museums, where it shows its versatility, since it can be found in institutions centered on a variety of topics, from local history ${ }^{3}$ to contemporary $\operatorname{art}^{4}$ and archaeological sites, ${ }^{5}$ including Egyptian collections. ${ }^{6}$

As is well known, the Temple of Debod was built by the Meroitic king Adikhalamani (c. 200-185 BCE) at a site $14 \mathrm{~km}$ south of the first cataract, and was devoted to the local manifestation of Amun and Isis. The last Ptolemies enlarged it and additions to the decoration and architecture were also made under the first Roman emperors. ${ }^{7}$ The Egyptian Republic presented it to the Spanish state, in acknowledgment of the aid given by the

\footnotetext{
1 On the objectives and first results, see Molinero Polo and Martín Flores 2009.

2 On the graffiti of Debod, see Molinero Polo et al. 2013.

Museum of London: http://www.museumoflondon.org.uk/ Resources/app/Streetmuseum-Londinium/home.html (accessed 1 May 2016).

4 Museum of Modern Art of New York: http://www.moma.org/ explore/mobile/iphoneapp (accessed 3rd May 2016).

5 Roman theatre of Medellin in: http://www.arsoft-company. com/armedellin/ (accessed 3 ( 16 ).

6 Musée du Louvre: https:/itunes.apple.com/us/app/musee-dulouvre/id337339103?mt=8 (accessed 3rd May 2016).

Martín Flores 2003; Molinero Polo 2015.
}

country during the campaign to rescue Nubian monuments and sites in the 1960s. In 1972 it was reconstructed in a central park of Madrid. In recent years it has become one of its main attractions for residents and tourists. According to the last annual statistics, it receives nearly 400,000 visitors per year, being one of the most frequanted monuments of the city. This number of visitors ma $\mathrm{t}$ an ideal place to test an educational project, such as the one presented here, since there is an evident social demand for contrasted information about the building and its history. In addition, the number and socio-cultural range of visitors afford an opportunity to check the validity of the new methods of cultural dissemination, which are more interactive, visual, and versatile.

Since its early stages of development, in 2004, the Tahut Project was defined by the application of methodologies based on new technologies for the documentation and epigraphic registration of the Temple of Debod. The project served as a field school for the training of epigraphists from several Spanish universities. Images for both the scientific study and the publication of the graffiti, reliefs and inscriptions have been created with the programs used for digital epigraphy. ${ }^{8}$ The most difficult examples to read have been digitally recorded ${ }^{g}$ Reflectance Transformation Imaging (RTI), and 3D r structions have been created to visualize our understanding of the building processes of the temple. It is, therefore, coherent with the work so far undertaken that the dissemination phase of the project should also be based on new information technologies. In parallel with the tool presented here, another very innor didactic medium has been also developed: an in-color, 2 cale reconstruction

\footnotetext{
8 Díaz-Iglesias Llanos and Méndez Rodríguez 2014.

9 A parallel to the application of this technique for graffiti can be seen in Frood and Howley 2014.
} 


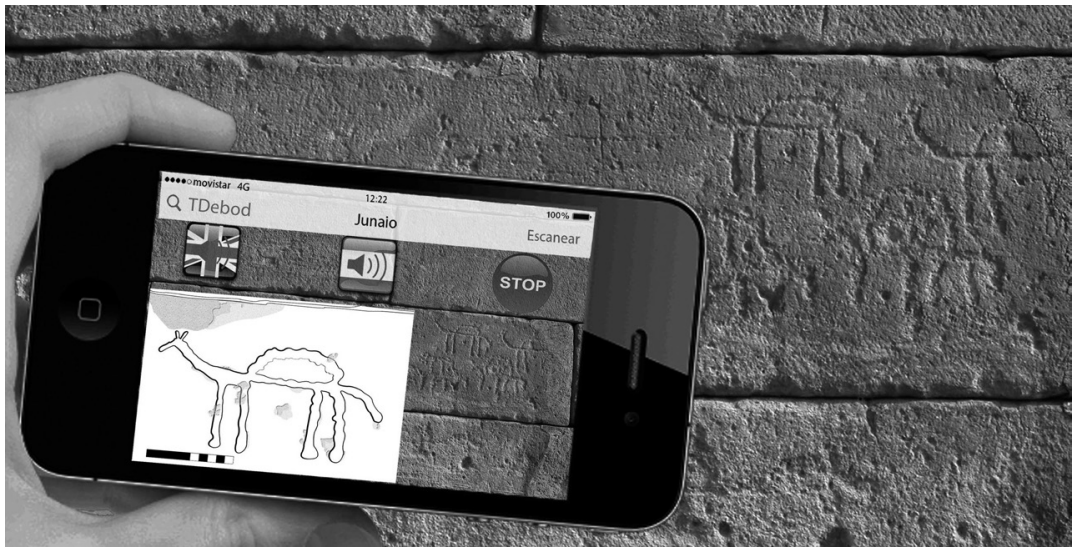

FIGURE 1: DEVICE WITH AR ACTIVATED IN THE TEMPLE OF DEBOD (๔ TAHUT PROJECT).
The advantages of applying AR in comparison with more traditional media of dissemination are:

a. opportunities to profit from the audio-visual possibilities offered by digital technologies in terms of communicating information;

b. the integration of different forms of information on Debod, gathered in the course of project development (old and recent photographs, videos, antique artwork, archival documentation, virtual reconstructions, etc.) in a single support source that combines actual format and easy handling;

of the Meroitic decoration currently on display $Q$ the exhibition Cleopatra y la fascinación de Egipto. ${ }^{10}$ This model features th ginal coloring $\rightarrow$ he figures, and a translation into Spanisnor the hieroglyphrcexts.

The long list of authors of this paper reflects that the team has become a multidisciplinary one. Since the inception of the project, and as the objectives gradually expanded, new professionals have been inc rated: to the initial group of Egyptologists, one of whor o specialized in museology, further specialists in architecture, graphic design, computing, and image processing have been progressively integrated. The University of La Laguna (Tenerife) and the Museum of San Isidro (Madrid) are the institutions around which the project is articulated. The funding, in two phases, is thanks to the Government of the Canary Islands, through its public call for research. ${ }^{11}$

\section{Why ‘Augmented Reality’?}

Augmented realit $\Omega$ AR) is a new technique that involves creating a combination of images in a technological device with a camera, such as smart-phones, tablets, or glasses, in which a real world environment, complemented with virtual elements, can be seen simultaneously. This combination creates a real-time mixed reality (Figure 1).

The members of the Tahut Project have considered AR technology as an opportunity to steer the team in the use of attractive new tools for the dissemination of research results. This technology has been first applied to the graffiti of Debod. These were among the initial study aims of the proje $\mathrm{d}$ their academic publication is currently in progress; in a communication on this subject was also delivered at the XI International Congress of Egyptologists in Florence. Selection of the graffiti also provides the opportunity to focus attention on a scarcely known element of the history of the temple, a subject that had not previously been studied, and with great potential in terms of historical information. In this way it fulfils the project aims of communicating to visitors and ac ics alike the new information developed in the course the rurch, and also doing it in a dynamic and attractive way.

\footnotetext{
${ }_{10}$ http://www.exposicioncleopatra.

11 Métodos digitales aplicados a la epigr,u. os relieves y graffiti exteriores del templo de Debod, 2003, reference 2003/120. Técnicas digitales aplicadas a las inscripciones y los relieves del templo de Debod, 2011, reference: Pro ID 20100235.
}

c. the ability to reach a broader age-range of visitors;

d. to make visits to the monument more attractive by the presentation of historical documents that are difficult to identify;

e. providing visitors with more freedom to enjoy the monument by receiving updated information without having to depend on a guide for the tour.

The application is available 24 hours a day, 365 day jear, although, obviously, the temple has an opening time for visits. However, in its current version, it can even be activated outside the building itself, as the application depends on a brochure for its display and the contents are stored in the 'cloud'. It can therefore be consulted before, during, and after the visit. In the near future, the contents will be displayed via a specific website, along with other results of our research project.

Understandably, this tool is not intended to replace the visit to the original monument, but rather to complement it. One of the issues that is currently being evaluated is whether the ion of these forms of applications will attract more visitors t $D$ temple, or if it will generate more virtual visits to the project website.

The system does have certain limitations and has to fulfil various requirements:

a. visitors are obliged to have a mobile device, i.e. smartphone or tablet with a $3 \mathrm{G}$ wireless data network, to relatively widespread technology nowadays, this

b. visitors of a certain age, or not accustomed to handling digital systems, may be reluctant to use it;

c. it is necessary to have a connection to a network for the reception of Internet data, and foreign visitors usually do not have this. In this case, the solution would be to act a local free 'wi-fi' or 'Bluetooth' for visitors, wh 2 ould be provided by the temple itself; 12

d. a certain level of basic training for the information and customer-service staff of the temple has been necessary, in order to help visitors who may require assistance in terms of installation and use of the application.

12 I.e. at the Museo Arqu 2 co Nacional in Madrid (MAN, National Archaeological Museum), with its free wi-fi available for visitors. enable a visit in this way. However, since this is a should not be a serious drawback; 

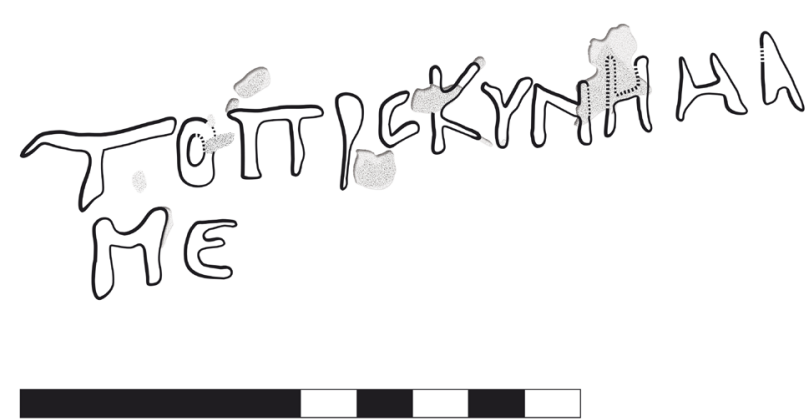

FIGURE 2: AN EXAMPLE OF A GRAFFITO DRAWING, AS DISPLAYED IN THE APPLICATION (C TAHUT PROJECT).

\section{The leaflet as support for the ‘Augmented Reality' facility}

For the visualization of the AR an image is necessary to activate the application, that is, to bring the virtual elements to the screen. In the most common system used in museums and heritage institutions, visualization is done through the image of the object for which the use of AR is intended: the application recognizes it - for example, a painting or an archaeological artefact - or a pattern associated to it - a code placed in its vicinity - and the screen of the mobile device displays additional inf $\equiv$ ion, while it shows the object itself at the same time,

The initial idea was that the ashlars of the temple, those with graffiti, would serve as the images that activate the application. This means that the element recognized by the digital tool would be the real environment; users could then move their electronic devices in front of the walls so that the virtual elements appear on their screens. However, this form of recognition could not be achieved because of two problems, one related to information and the other to the technology.

First, the main problem is that graffiti are not easily distinguished on the walls of the temple: those on the outer walls, because it is either too bright or they are in shaded areas; and those in the inner chambers, because it is too dark. It has to be kept in mind that when the external graffiti were traced, the carved strokes could be seen thanks to their colour, contrasting with the surrounding stone surface. The inner ones had natural light, as the chambers had lost their ceilings, but given that the roof has been replaced, the walls are now in darkness. Nowadays, to see the majority of these graffiti it is necessary to create specific lighting conditions. The result is that visitors do not know where they have to look for them, given that there are not on every wall and that they are not easily distinguished at first glance.

The second difficulty is that the surface of the ashlars is too homogeneous and their edges are very similar. In addition, the graffiti were carved on smooth walls, where it was easy to trace them and they were more visible at that moment. The consequence is that it is nearly impossible for the digital tool to distinguish one ashlar from another as they do not present enough distinct differences to allow the application to operate.

For these reasons, in this first phase of the project - while a different and better solution is devised - the medium that sets the application running is a folded, paper leaflet (Figure 3). This support is well suited to our current needs as it fulfils the following requirements:

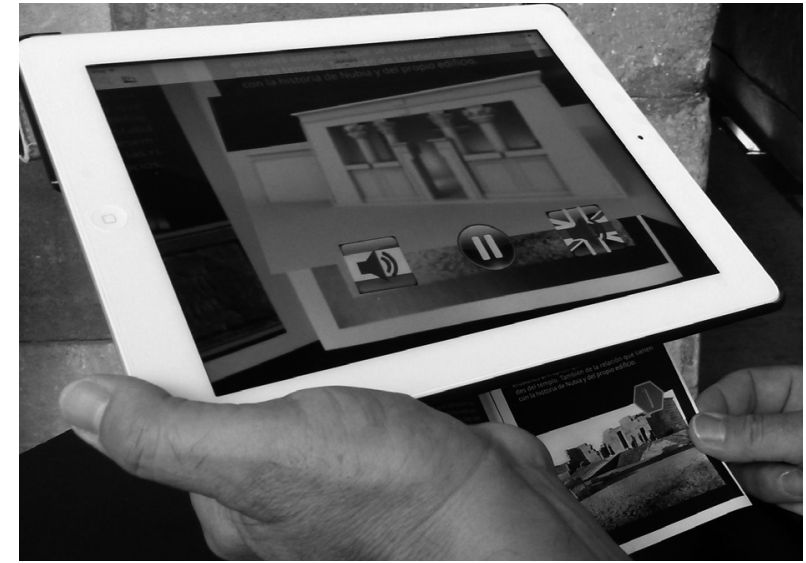

FIGURE 3: THE TOUR LEAFLET'S NUMBERED IMAGE, CAPTURED BY THE TABLET, ACTIVATES THE VIDEO SHOWING THE BUILDING'S HISTORY (C TAHUT PROJECT).

a. it is economical to reproduce;

b. it is easy for every visitor to man tute;

c. it encourages users to discover the temple in a pleasant way;

d. it helps visitors to acquire the habit of employing an application to learn more about the Temple of Debod. The goal is to gradually extend this tool to other subjects being studied in the project, i.e. the reliefs, the inscriptions, and the blocks exposed under the roof, those that have not been replaced in their original locations. They will be incorporated into specific applications in a parallel development of research into the history of the building and other digital dissemination methods;

e. the leaflet can also fulfil an additional task when the visitor has left the temple by helping to publicize its contents. The application be activated again at home, where the visitor $\&$ atch and listen again to the information in the AR. The contents can be further made available to other individuals who might thereby also become interested in the monument. Additionally, this will show the advantages of interactivity prompted by the use of AR, given that its display is not dependent on the real environment but on the leaflet, and, in this way, also available for persons who have not yet visited the site.

It must also be said that a new phase of the project has been launched to solve the problem of identifying the ashlars, either by QR codes displayed on the floors, or on stands, or through GPS, relying on a 3D reconstruction of the monument. However, this stage is currently under experimentation and development by IT technicians.

\section{Contents of the leaflet and the application}

The leaflet (Figures 4 and 5) provides visitors with brief, written information: one paragraph is dedicated to the Temple of Debod in its original location and its transfer to Madrid, with some further information about its graffiti in general. There is also a set of images, through which specific forms of these unofficial carvings are represented, each complemented by a number. Without these numbers the application would be unable to distinguish among the photographs of the ashlars, a problem already encountered 

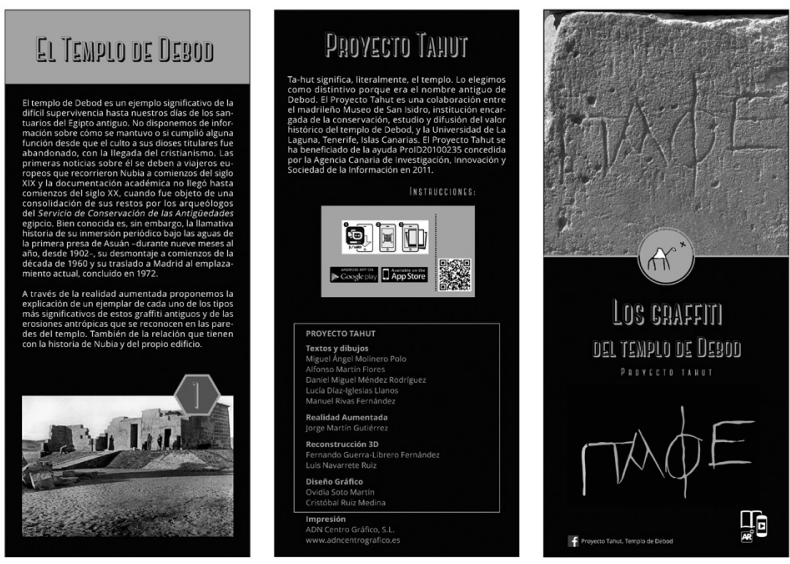

FIGURE 4: FOLDED TOUR LEAFLET (FRONT PAGE)

(C TAHUT PROJECT).

in the real environment (see above). With only one exception, the pictures are organized in chronological order, following our interpretation of the graffiti, from the oldest to the more recent ones. Thus, the leaflet suggests a possible tour around different parts of the building and the type of secondary carvings in them. In addition, it also contains a plan of the temple to locate the chosen elements, so that visitors can organize their tour in a different order if they prefer.

Although there may be more than one graffito on a single wall, the photographs in the brochure, and the drawings and information of the AR, help visitors to recognize the one being explained. Nevertheless, some interactivity is obliged: the visitor has to find the item on the wall, and the visit becomes more participative.

Each of the leaflet's numbered photographs is the element that activates the specific information on AR. It reaches the visitor in two sets that make up the core of this audio-visual device: additional images of various types (including a video) and texts. The textual information is provided as an audio, in order to facilitate its reception by the user. It is well known tha ring an explanation is more comfortable than reading it. $\overline{\bar{u}}$, therefore, more didactic. The application is created incorporating the possibility of listening to the texts in two languages, Spanish and English.

The information is organized in eight sections, i.e. there are eight pictures in the brochure, each of them activating its corresponding audiovisual information on AR.

Number 1 explains the construction of the Temple of Debod. The AR includes a map of Nubia with the location of the building, and a video with a virtual tour that goes from the current situation of the sanctuary back in time to the building of the central chapel by the Nubian king Adikhalamani. The audio gives a brief explanation of the historical context in which the different construction phases were carried out, from the Meroitic period to the last Ptolemies, and the Roman decoration of the vestibule.

Numbers 2 to 8 show the seven most common types of graffiti and alterations produced by human activity on architectural surfaces. Of the nearly 200 items identified on the walls, those considered more significant have been selected. There are several criteria for these selections: the historical information they provide, their visibility on the walls, or their particular
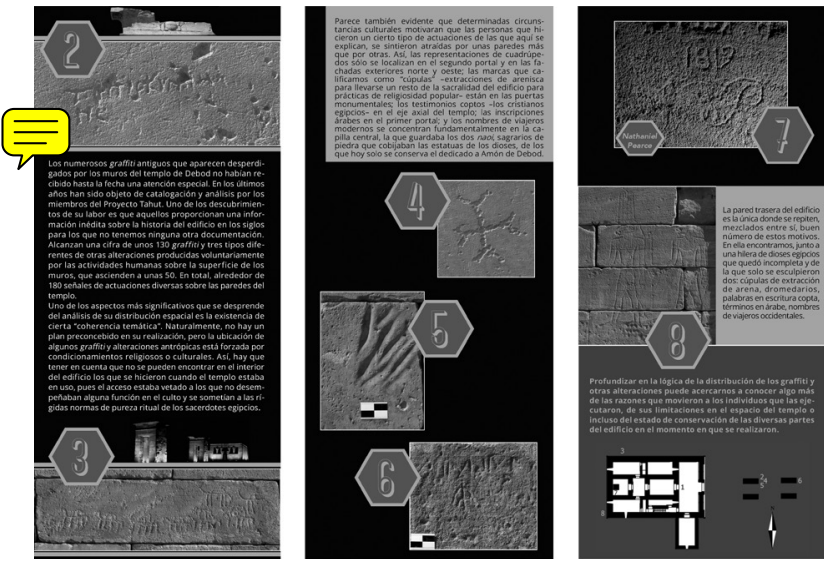

FIGURE 5: FOLDED TOUR LEAFLET (REVERSE)

(C) TAHUT PROJECT).

uniqueness. It was not possible to include all categories of graffiti. ${ }^{13}$ Those presented in the brochure are:

- the only Greek graffito currently preserved: toproskynema;

- the Blemmyan dromedaries of the north wall;

- one of the Coptic patée crosses (the easily visible one on the door of the second pylon);

- fusiform grooves, of undetermined date, from the outer walls;

- a set of Arabic graffiti written on the door of the first pylon;

- the name and date of Western travelers, most of them carved in the chamber where the two naoi originally stood;

- the relief of two gods on the western wall with rounded grooves around their feet.

For each of these categories, the audio gives information organized in a similar format: the historical framework in which the specific type of graffito is generated; the location of these graffiti in the temple, if similar specimens occur in precise spaces or walls, which is very commor d an explanation of a particular example, i.e. from among the leaflet's illustrated images. The AR always includes, at least, a drawing of the graffito explained in detail, as well as additional iconographic information.

\section{Development and working of the application}

The application has been developed with the Augmented Reality' module Metaio Creator Version 6.0.

The most laborious part of any application of AR is the creation of the virtual contents. In this case, some of the material was already generated during the working process of the Tah Pject: the photographs and drawings of the graffiti, as we the historical research on the building itself, which has enabled the creation of the 3D virtual model shown in the video. The specific work for the application included the selection of what to display and the writing of the texts for the audios (in its Spanish and English versions). The audio includes appropriate background music to augment the listening experience.

\footnotetext{
${ }^{13}$ For a typology of these marks, see Molinero Polo and Martín Flores 2009: 111-3, 346-7.
} 
Once the virtual material was created, the images that have to function as patterns of recognition were programmed with Metaio; these hergme the numbered graffiti pictures in the brochure. Eacl 0 tern was then associated with the images to be shown virtually, as well as two additional icons (two flags: Spain and UK). (t) activity is applied to every icon, so that the audio assigneuco each specific graffito is activated when pressed. The speech can be interrupte ny time by pressing the pause button or by pressing on her flag to change the audio language.

To prevent visitors from having to have a specific application of AR created for Debod, the contents are stored in the 'cloud' and the free-viewer Junaio is provided. This is a generic application that displays any AR information. Application developers create channels - a channel being an application of AR. It is only necessary to prompt Junaio with the channel required and the user will receive the contents on his/her tablet or smart-phone.

If, nevertheless, the visitor does not have the Junaio application on his/her device it will be necessary to install it. It is available for Android and iOS, and must be downloaded from 'Playstore' or 'AppStore'. If the equipment is already provided with a reader of $\mathrm{QR}$ codes, it can be used to read the one in the leaflet; this will download the application and the installation process takes no more than a minute.

Once Junaio is installed it must be accessed, and the search for the specific channel for Debod has to be launched: in this case it is called 'TDebod'. Another possibility is to view on the device screen the QR code provided in the brochure, press the scan button, and activate the application; it is possible to go then directly to the AR contents. At the top of the screen, the channel icon (an image of the Temple of Debod) is displayed. The camera is activated so that the only thing the visitor has to do is to capture the leaflet's numbered images. Automatically and without further action, overlapping virtual contents appear and the user can activate the audio.

\section{Reception by the visitors}

The leaflet has been available, free, at the temple since the middle of August 2015. In September an advertising campaign was launched - in the temple itself and through social networks - to reach potentially interested individuals and encourage them to make a tour and learn about the historical graffiti of the building. A short questionnaire was also prepared to evaluate the operability of the system from data supplied by actual users, as well as to determine the degree of satisfaction with the whole application and the possible problems met.

Several issues were identified by this research. The first one, and fundamental, has been th large number of visitors interested in the graffiti pre $\sim$ to take the leaflet away with them and run the application later, rather than use it in the temple itsel 1 means that one of our prime objectives - that visitors 1 at the graffiti on the walls, listen to the information provided, and identify similar examples in the rest of the building - has not been met. The consequent level of understanding of the temple intended by the system has not therefore been maximized. The discomfort caused by crowding, as well as the long queues to enter the monument, and the convenience of listening to the explanations more comfortably at hom ${ }^{\text {em }}$ to have been decisive factors in peoples' choices.

Moreover, the module in which the application was created, Metaio, has been acquired by Apple; as a result, the application was in 7 pted in the winter of 2016. At the time of writing the find sion of this article, the first version of the application is no longer running.

Both problems will be solved by the second version of the application, currently in the process of development. First, the use of AR as a support to provide information to visitors will be maintained; and the new version is being created with a different program, to avoid operational problems. Second, codes or images that trigger the application will be fixed in the temple, so that vis have to activate them in front of the relevant wall wherc the graffito informed by the AR is located; thus, the need to use the brochure is avoided and visitors are forced to identify the items in the temple itself. However, for those who wish to obtain the information through a more conventional system, the contents of the old leaflet will be hosted on the website of the project, so that it can still be accessed from anywhere with an Internet connection.

In conclusion, the project has lea rom the problems encountered by the first version of $\_$pplication, and has converted the negatives identified into a positive: the creation of a second version, in which necessary improvements are being introduced. Moreover, the planning of the next phases of the project's dissemination is being devised, taking into account these experiences. Future applications will not only include new series of graffiti, reliefs and inscriptions of the temple, they will also be integrated within a forthcoming museographic project forth monument, in which AR will be incorporated into the fo visiting/tour experience of the Temple of Debod.

\section{Bibliography}

Díaz-Iglesias Llanos, L. E. and Méndez Rodríguez, D. M. 2014. Digital epigraphy of the temple of Debod. Egyptian Archaeology 45: 39-41.

Frood, E. and Howley, K. 2014. Applications of Reflectance Transformation Imaging (RTI) in the Study of Temple Graffiti. In E. Pischikova, J. Budka and K. Griffin (eds), Thebes in the First Millennium BC: 625-38. Newcastle-uponTyne, Cambridge Scholars Publishing.

Martín Flores, A. 2003. El templo de Debod. In Nubia. Los reinos del Nilo en Sudán: 108-12. Barcelona, Fundación La Caixa.

Molinero Polo, M. A. 2015. Debod, un templo egipcio en Madrid. Fases de construcción y programa decorativo. In Cleopatra y la fascinación de Egipto: 140-5. Milán, Skira.

Molinero Polo, M. A. and Martín Flores, A. 2009. Proyecto epigráfico en el templo de $\mathrm{d}$ /Epigraphic Project in the Temple of Debod. In M Pérez-Díe (ed.), 120 años de arqueología española en Egipto / 120 years of Spanish Archaeology in Egypt: 108-15, 345-9. Madrid, Sociedad Estatal de Conmemoraciones Culturales.

Molinero Polo, M. A., Martín Flores, A., Ruiz Medina, C., Méndez Rodríguez, D. M. and Díaz-Iglesias Llanos, L. E. 2013. Los grafitis del templo de Debod. La aventura de la Historia 174: 72-6. 